\title{
A Final Year Design Course Based On Industry Derived Projects
}

\author{
By \\ Greg J. Schoenau, Professor \\ Mechanical Engineering Department \\ University of Saskatchewan \\ Saskatoon, SK S7N 5A9
}

\begin{abstract}
This paper describes a two term design projects course in the Mechanical Eng. Dept. at the U of S. It is considered to be a "flagship" course for students in the final year of their program. Students focus on solving design problems submitted by industries and other outside organizations. Each student group works on a separate and unique project. The course provides students with an excellent opportunity to apply their engineering analysis and design theory. They function as a team, typical of practicing consulting engineers. They are responsible for the direction and quality of the work performed. Faculty act as technical advisors to the students, not as supervisors. The student groups search the literature, brainstorm design alternatives and analyze and test promising alternatives. A final report and seminar presentation are required for every group as well as periodic progress reports and presentations. Students get to work on a "real world" problem, typical of exactly what they might experience after graduation. This is really an extremely important and crucial distinguishing feature of the course and serves as a strong motivator for the students. The course therefore acts as a bridge between a student's academic training and their practice of engineering. For industry, it is an opportunity to investigate the feasibility of a new design, process or method of production for minimal cost.
\end{abstract}




\section{Background}

A design project type course has been part of the curriculum of the Mechanical Engineering Department at the University of Saskatchewan for many decades. Initially it was a one term course situated in the final semester of the final year of studies. Projects were all based on suggestions or problems submitted by faculty. Often they were based on consulting or research related projects that the faculty had experienced or undertaken. As the department became more research intensive, many more projects were derived from faculty research interests and were considered as an effective means to attract students into graduate studies. They tended to involve only one or two students in their execution.

This approach to a design course often resulted in problems with a substantial analytical component, however the work was often lacking any other aspect with the exception, perhaps, of some experimental work. Students were seldom exposed to much in the way of group dynamics. Since the problems were posed by faculty, the "open-ended" aspect, so important in real world problem solving, was often missing with the traditional faculty - student teacher role model prevailing and the professor providing most of the guidance and expertise.

In the 1980's, integrating a larger component of design into the curriculum became an important mandate. The design projects course was revised to address many of the above concerns and, in a short time, evolved into its present format.

\section{Course Description}

The present course covers two terms and is considered the "flagship" course for students in the final year of their program. All projects are derived from industries and other outside agencies such as hospitals or sporting organizations. Appendix A contains a representative list which portrays the typical range of projects that the students have undertaken over the past few years. The sponsoring agency is also listed.

In early summer organizations are contacted and encouraged to submit a project. For companies that have participated in the past, this constitutes more of a reminder. Prospective new organizations are supplied with an additional information package providing a fairly extensive background description about the course and our expectations from them. Many of these companies have heard about the course from someone else or made inquiries to the Department about the possibility of students working on a specific project for them and been directed to the course coordinator. A company contact person must be named on the submission with this person usually also filling the role of student advisor for the organization. The Department provides a modest budget of $\$ 300 /$ group as well as some free machine shop time. The companies are required to cover any travel costs as well as any additional costs beyond the Department level for items such as prototype construction. They have complete access to college laboratory facilities, equipment and instrumentation.

Projects are screened for their suitability by the coordinator in consultation with faculty who are more familiar with the particular associated subject area. A list of approved projects and their descriptions are provided to students at the beginning of classes. Students are allowed to organize themselves into groups of three or four with the actual numbers dependant on total course enrolment. Within the first two or three weeks of classes, students select their project. This is done by means of a lottery with the group names being drawn from a hat. Students are thus required to prioritize as many as five or six projects that they are interested in pursuing. We usually strive to have a few more projects available than groups so those at the end of the draw still have some choice. At this point a faculty advisor is assigned to the group based on the faculty member's background and interests. All faculty in the Department generally participate.

Students are required to make a site visit to the organization as soon as possible to collect further background information on their design problem and meet their industrial contact. About six or seven weeks into the course the students give their first progress report. This takes the form of both a brief (3page) written report as well as a short $(8 \mathrm{~min})$ presentation to class. It is expected that at this stage students will have a clear understanding of the problem and identified all constraints. A more extensive progress report (again both written and verbal) occurs about 2/3 the way through the course. The verbal presentation could be considered more of an oral exam since the time allotted for questions exceeds the time for the presentation. 
The student grades are composed of inputs from various sources. The grade breakdown is given below:

\begin{tabular}{lr} 
Written Progress Report \#1 & $2.5 \%$ \\
Seminar Presentation \#1 & $2.5 \%$ \\
Written Progress Report \#2 & $5.0 \%$ \\
Seminar Presentation/Examination & \\
On Report \#2 & $10.0 \%$ \\
Final Seminar & $10.0 \%$ \\
Logbook & $10.0 \%$ \\
Final Design Report & $30.0 \%$ \\
Technical Assessment & $10.0 \%$ \\
General Assessment & $20.0 \%$ \\
\multicolumn{1}{c}{ TOTAL } & \\
&
\end{tabular}

The seminar grades are a composite of evaluations obtained from all faculty and staff attending using forms created for this purpose. The progress reports, final report and logbook are graded by the faculty advisor. The company advisors are invited to make comments and submit a grade, if they wish. Past practice has indicated that some people view this as a burden and is an area in which they generally lack experience. However, the faculty member takes into account their comments in the assessment of the final report. The technical assessment is performed by another faculty member who will evaluate one other project based on a review of the final design report. All of the final reports are evaluated by one faculty member in order to provide a more comparative evaluation. The grade that this person assigns each project appears in the General Assessment component of their grade. Finally students are given the opportunity to confidentially evaluate the contribution of each member, including their own. The faculty advisor also performs an assessment of the overall contribution of each student. These assessments are used to calculate a "factor" which is used to modify the grade of each student. Students are made aware of the departure in their grade from the mean. An opportunity for an appeal to the course coordinator and Dept Head exists. Fortunately, most student groups assess an equal contribution to each member and appeal hearings are rare.

The seminar is a day long event and is held off campus to provide a more professional and business-like setting for the event. All mechanical engineering classes are cancelled that day so all undergrad students as well as faculty and staff can attend. Representatives of the organizations are invited to attend as well as local practicing engineers.

In terms of proprietary rights, the sponsoring organization has ownership of the material. No confidentiality agreement exists and the material is generally considered in the public domain. However, the Department does not provide copies of the reports to anyone unless they have the permission of the sponsoring organization. Many of the outcomes of the projects have been directly applied to their operations and the organizations have returned the following year with a project submission based on continuing the work.

\section{A Discussion of Pros and Cons of the Course Structure}

Some of the motivating factors and therefore the positive aspects of this type of course have already alluded to in the previous section but are discussed here in more detail. Some problem areas that arise with this course structure are also be examined.

Benefits to the students are many and significant. They get to work on a "real world" problem, typical of exactly what they might experience right after graduation as they enter the work force. They are expected to function as a group of consulting engineers and they experience all of the interpersonal dynamics associated with group work. Since the projects originate from industry rather than faculty, students are required to think for themselves and develop their own solutions with the faculty and industrial contacts acting purely as advisors, remover from their traditional role as "expert". The open ended nature of these problems requires them to "think outside the book", demanding both more creativity and discipline. The level of student motivation is also increased by the fact that the results of their project have a commercial interest and is not just an academic exercise. Student projects from this course have won awards in many design project competitions over the years.

The development of a student's ability to communicate effectively, both orally and in written form, does not likely receive the attention that it deserves in most engineering programs. The seminars and reports required for this course serve as a laboratory for students to further hone and develop these skills.

For the participating industries, the course provides an opportunity to investigate the feasibility of a new component design, process or 
method of production at minimal cost. They also have access to college equipment and resources which otherwise would not be available to them. The outcome of these projects has often been directly applied to the operations of the organizations. They also benefit by the opportunity to observe first hand a group of engineering students in action and this has led directly to job offers to one of the students.

As would be expected, a diverse set of projects is generated from submissions from a diverse set of organizations. This lack of homogeneity generates interesting projects but do not always provide the student with the complete design experience, particularly when it comes to seeing their complete design constructed and tested. There is not enough time and/or the prototype is too expensive. This diversity can also lead to design problems where there is a very substantial component of analysis or generates projects where effective solutions require only "catalogue engineering". Maintaining consistency in faculty evaluation over such a range of outcomes can be problematic.

Also, the exact nature of the problem may not be apparent from the initial documentation provided by the organization resulting in a problem definition that can seem overwhelming. A lesser amount of work involving a reduced scope is usually negotiated. A greater concern is a proposed problem for which a satisfactory but somewhat trivial solution exists. These deficiencies are not always detected in the screening process.

\section{Concluding Comments}

A two term final year design course is described. The course uses screened projects submitted by outside organizations which represent entry level engineering design type problems. Students assume a leading role in deriving solutions with both faculty members and industry contacts acting as advisors. The course is considered a good means of providing a bridge between the student's academic studies and the type of "open -ended" engineering problems that they are likely to encounter when they first enter the engineering work force. However, with the diversity of projects involved the total design experience can be limited.

\section{Appendix}

This appendix contains a representative selection of the design projects that have been undertaken as part of this course over the past several years. The sponsoring organization is also listed.

\begin{tabular}{|c|c|}
\hline Project Title & Sponsoring Agency \\
\hline $\begin{array}{l}\text { Joystick Control } \\
\text { of an ATV }\end{array}$ & A to Z Graphics \\
\hline $\begin{array}{l}\text { Automatic Bratice } \\
\text { Nailer }\end{array}$ & $\begin{array}{l}\text { Agrium's Vanscoy } \\
\text { Potash Operations }\end{array}$ \\
\hline $\begin{array}{l}\text { Wind Turbine } \\
\text { Aerodynamic Brake } \\
\text { System }\end{array}$ & $\begin{array}{l}\text { Atlantic Orient } \\
\text { Corporation }\end{array}$ \\
\hline $\begin{array}{l}\text { Modification of a } \\
\text { Mechanical Harvester } \\
\text { Research For } \\
\text { Saskatchewan Native } \\
\text { Fruits }\end{array}$ & Bantle Engineering \\
\hline
\end{tabular}

Easy Height Adjust Bourgault Industries

Ltd.

System for the

Bourgault Coulter

Mid-Row Bander

An Improved Balloon

Catheter for a

Stenosed Coronary

Artery

Design Vehicle

Exhaust Extraction

System for Biogas

Application to

Conventional

Diesel Engines

Development of a

Low Cost Belt

Tightener for a Belt

Drive Ventilation

Fans

Aerial Ignition

Device System

Design of Loading

Pocket Dust Control
Bregman International Trading Co.

Clear-Green

Biotechnologies/

BDI

Del-Air Systems

Forest Engineering

Research Institute of

Canada-Wildland Fire

IMC Potash 